\title{
Teaching English for Undergraduate Students: Motivational Aspect
}

Grigoreva E.V. ${ }^{a}$

\section{Solodkova I.M. ${ }^{b}$}

a b Kazan Federal University, Institute of Management, Economics and Finance, Kazan, 420008, Russia

Email: imsold@mail.ru

\section{Doi:10.5901/mjss.2015.v6n1s3p341}

\section{Abstract}

The paper dwells on the importance of motivational aspect in a foreign language acquisition within undergraduate course. Motivation is viewed as a foremost aspect in acquiring high language proficiency level and its correlation with future career prospects. To identify the level of motivation a two stage questionnaire survey was organized with undergraduate students of Kazan Federal University. It proved the strategies described in the paper as well as defined the motives which could act as recommendations in designing the syllabus.

Keywords: motivation, language acquisition, undergraduate students.

\section{Introduction}

All activities people perform are driven by some forces which come either from inside or outside. Motivation is a complex, actively and continuously discussed phenomenon which found its reflection in all actions observed in the society, whether we speak about professional, educational or everyday matter. If in psychology it refers to as initiation, direction, intensity and persistence of behavior [Geen, 1995]. As well as, to the factors that activate, direct, and sustain goal-directed behavior [Nevid, 2013].

In education, motivation is given a characteristic of an internal drive which pushes someone to do things in order to achieve something [Harmer, 2001]. Although, Penny Ur thinks that this term is easier to be explained from the point of view of 'motivated student'. This is the one who is willing or even eager to invest effort in learning activities and to progress [Ur Penny, 1996].

We agree with the viewpoint that motivation in education can't be fully explained through psychological glance alone. To understand what motivation in education is we have to appeal to the specialized setting of education and look at its qualitative differences.

Motivation and success in education are interconnected. Success in a foreign language acquisition is linked to motivation in particular. As well as Gardner, R.C., Dornyei, Z., Oxford, R.L., \& Shearin, J., we believe that attitude and motivation play a major role in a foreign language acquisition [Dornyei, 1990; Gardner, 1985; Oxford \& Shearin, 1996]. Foreign language is a subject that is needed in constant motivational level especially if is acquired in simulated, unreal conditions lacking the communication with native speakers.

All subjects (excluding the practical course of a foreign language) within the curriculum of non-linguistic higher educational establishments (HEE) in Russia are taught in Russian language (admitting, though, some exceptions, which depend on the concrete HEE). However, increasing collaboration, exchange programs, have made universities introduce a recent trend of reading lectures of major specialties, like economics, management, in a foreign language, preferably English. University education in Russia is becoming more mobile, it strives to meet the needs of social and economic development [Galishnikova, 2014]. It happens not only because of the 'transition to Bachelor-Master Degree structure but also the introduction of new Educational Standards' [Ismagilova and Polyakova, 2014]. 'University graduates should be able to interact cross-culturally, participate in international mobility programs and scholarships' [Gorelova, 2014].

In connection with this, HEEs have to solve several problems. Firstly, how to make students interested in a foreign language acquisition from the beginning of their undergraduate course and keep it on just about the same level up to the end of it. Students have to 'get education corresponding to international standards inside their own higher education institution' [Grigorieva, 2014].

Secondly, HEEs have to define main motives the students have to a foreign language acquisition and on their 
basis to compose main components of substantive motivation.

\section{Discussion}

Foreign language acquisition at HEE is a challenging task for some undergraduates. It could be explained by difference in overall language proficiency level that students possess, their negative experience in learning a foreign language, emotional component, etc. So, at the beginning of undergraduates' education experience they have to be tested and the answers are to be thoroughly analyzed. Moreover, educators should be aware of finding out students needs, as this information will certainly help with academic success [Whyte, 2007]. Having known the needs teachers may design assignments, in-class activities, and discussion questions to address these kinds of needs [McMillan and Forsyth, 1991].

When teachers get the complete picture of the undergraduates they are going to work with they could set expectations. Expectation have to be realistic, easy to be achieved but challenging and stimulating. Standards that teachers introduce could be high enough to motivate undergraduates but not unapproachable. To develop the drive to achieve, students need to believe that achievement is possible - which means that you need to provide early opportunities for success [American Psychological Association, 1992; Forsyth and McMillan, 1991; Lowman, 1990]. Explaining what undergraduates should do to succeed in a foreign language acquisition, strengthening their positive sides could bring adequate motivational results in the long run. Inclinations and emotions, attitudes and ideals can serve in the role of the motive [Kudryavtseva, 2014].

Unfortunately, there is still no unique formula for the development and improving motivational level. Many factors could affect undergraduates motivation: interest in the subject matter, perception of its usefulness, general desire to achieve, self-confidence and self-esteem, as well as patience and persistence [Saas, 1989]. Teachers and educators could appeal to the motives. To study a foreign language in HEE means to associate your language skill with your future career in a certain professional field. Not all students can do that. Some undergraduates express the idea of uselessness of a foreign language skill for their future career. While studying, undergraduates have two closely connected and interrelated motives: academic and professional. Professional motives equal the result of an educational program whether academic motives are found within the process of education. Undergraduates tend to be stronger motivated when they have specific rather than general goals for a foreign language acquisition. Motives could be of intrinsic (produced by a person himself) and of extrinsic (outside impacts) origin. Undergraduates are said to be intrinsically motivated if they: attribute their educational results to factors under their own control; believe they have the skills to be effective agents in reaching their desired goals, also known as self-efficacy beliefs; are interested in mastering a topic, not just in achieving good grades [Wigfield, Guthrie, Tonks, Perencevich, 2004]. Extrinsic motivations could be positive or negative. Common extrinsic motivations use at educational process are: rewards, competition, punishment, high/low grades, grants, etc. Factors that motivate undergraduates may change over their lifetime.

Gardner R. C. and Lambert, W. E. distinguish two types of language learning motivation: instrumental and integrative motivation [Gardner and Lambert, 1972]. Instrumental motivation is characterized as the desire to obtain something practical or concrete from the study of a second language. Instrumental motivation underlies the goal to gain some social or economic reward through L2 achievement [Hudson, 2000]. Learners with an instrumental motivation want to learn a language because of a practical reason such as getting a salary bonus or getting into college [Lesson2, 2014]. Undergraduates usually have a clear instrumental motivation for language learning because they strive for fulfillment the HEE's requirements. Integrative motivation is identified as the learner's orientation with regard to the goal of learning a second language [Crookes and Schmidt, 1991]. Those undergraduates who have integrative motivation, learn a foreign language to be able to use it as a source of communication and knowing the people and culture of this language. See Table 1 [Bailey, 1987].

Table 1. Differences in integrative and instrumental motivation

\begin{tabular}{|l|l|l|}
\hline & Intrinsic & Extrinsic \\
\hline Integrative & $\begin{array}{l}\text { L2 learner wishes to integrate with the L2 } \\
\text { culture (e.g., for immigration or marriage) }\end{array}$ & $\begin{array}{l}\text { Someone else wishes the L2 learner to know the L2 for integrative } \\
\text { reasons (i.e., Japanese parents send kids to Japanese- language } \\
\text { school) }\end{array}$ \\
\hline Instrumental & $\begin{array}{l}\text { L2 learner wishes to achieve goals } \\
\text { utilizing L2 (e.g., for a career). }\end{array}$ & $\begin{array}{l}\text { External power wants L2 learner to learn L2 (e.g., corporation sends } \\
\text { Japanese businessman to U.S. for language training). }\end{array}$ \\
\hline
\end{tabular}

It is really helpful when teachers assist undergraduates in developing more specific goals for foreign language 
acquisition. Teacher could act as a 'consultant who has the knowledge of communication practices but needs to negotiate with the students on how best to explore these practices to meet the objectives they have' [Solodkova, 2009]. The identification of motives could help educators formulate suitable motivational techniques. Though, it could be a hard thing to do due to the personal differences of undergraduates.

There are general motivational strategies approved by many researches as: Lowman J., Weinert F. E., Bligh D. A., McMillan, J. H., and Forsyth, D. R., Sass E. J. [Bligh, 2000; Lowman, 1990; McMillan and Forsyth, 1991; Saas, 1989; Weinert and Kluwe, 1987]. To make undergraduates interested in a foreign language acquisition, to help them identify preferences and attitudes to life and set connections between foreign language and future career, educators take into account: the usage of different teaching methods and forms of learning a language; the creation of positive atmosphere and rapport in the classroom; the enthusiasm of the teachers; the relevance of the material studied; professional component of tasks; well-planned language lessons; setting challenging tasks; clear undergraduate/teacher expectations; delivery of real incentives; proper and quick feedback. Communicative competence can be achieved by: 'proper guidance, facilitation, motivation and collaboration' [Zalyaeva and Solodkova, 2014].

Appeal to positive emotions, creation of true to life atmosphere, where undergraduates feel closer to foreign language environment will certainly be reflected in high motivational and language proficiency level.

\section{Methods and Approaches}

Theoretical analysis, observation, the investigation of progressive pedagogical and psychological experience, questionnaire, and comparison were used in this research.

The aim of the research was to find out what motives, extrinsic or intrinsic, for foreign language acquisition prevail among the first and fourth-course undergraduates to assist teachers in choosing the right tactics and so, to increase the quality of education process, i.e. to help teachers of English model their activity according to the needs and motives of students and design syllabus.

The survey was conducted from March 2014 to October 2014 at the Institute of Management, Economics and Finance of the Kazan Federal University, General Economics division. The questionnaire was completed by 64 first-year undergraduates of which $40(62,5 \%)$ were female and $24(37,5 \%)$ were male, and 71 fourth-year undergraduates of which $44(62 \%)$ were female and 27 (38\%) were male. They were surveyed anonymously. The choice of courses, in particular the first and the fourth, is determined by necessity to compare the results of respondents who are at the beginning of their study at HEE and respondents who have been studying for some years at HEE to solve the problem of this research. The questionnaire results were analyzed by quantity and quality.

The questionnaire comprised 11 questions with variants of answers to choose. There were 2 types of questions: closed questions requiring the students to circle 'yes' or 'no' answer and open question which supposed students to choose the variant which appeals to them.

\section{Results}

The researchers tried to find answers for the questions specifically suited to the aim of the research, like: undergraduates' personal motives for foreign language acquisition (Q4); factors influencing on undergraduates' in their English language acquisition (Q5); techniques and methods making English classes motivating (Q6); conditions contributing to student's motivation (Q7); (Q8) is designed to find out which of the tasks students prefer during their English language classes; (Q9) concerns a positive atmosphere in the classroom; (Q10) is devoted to find out if motivation is a teacher's priority alone; the satisfaction of undergraduates' personal and professional interests and motives through Foreign language teaching at HEE (Q11).

The data analysis of the responses to the questionnaire provides the researchers the following results in percentage received shown in Table 2.

Table 2. The ratio of extrinsic or intrinsic motives for the first and fourth-year students

\begin{tabular}{|l|c|c|}
\hline Type of motives & First-year students & Fourth year-students \\
\hline Extrinsic & $62,5 \%(40$ чел.) & $29,5 \%(21$ чел.) \\
\hline Intrinsic & $37,5 \%$ (24 чел.) & $70,5 \%$ (50 чел.) \\
\hline
\end{tabular}

Thus, quantitative analysis results in prevalence of extrinsic motives of the first-year students who usually don't realize 
the importance of foreign language acquisition for their future professional life at the beginning of undergraduate course and learn a foreign language to be able to use it as a source of communication for their personal purposes and knowing the people and culture of this language, not to be punished by their parents or teacher. Just as, the fourth-year undergraduates have intrinsic motives to a great extent that is explained by their realization that the modern society requires foreign language skills for associating with students' future career, prosperity in a certain professional field and their competitiveness on the labor market.

Interpretation of the main factors influencing students motivational level showed the almost equal percentage chosen by both first-year and fourth year students. See Table 3.

Table 3. The ratio of motivational factors

\begin{tabular}{|l|c|c|}
\hline Motivational factors & First-year students & Fourth year-students \\
\hline enthusiasm of the instructor & $20,3 \%$ & $19,7 \%$ \\
\hline relevance of the material & $12,5 \%$ & $12,7 \%$ \\
\hline variety & $19 \%$ & $18,3 \%$ \\
\hline active involvement of students & $14 \%$ & $15,5 \%$ \\
\hline rapport between teachers and students & $7,8 \%$ & $11,3 \%$ \\
\hline appropriate difficulty level & $4,6 \%$ & $12,7 \%$ \\
\hline all factors & $21,8 \%$ & $9,8 \%$ \\
\hline
\end{tabular}

\section{Conclusion}

On the basis of the considered theoretical and experimental data, we have concluded that teaching English for undergraduate students in its motivation aspect includes the following conditions:

- taking into account students' needs, their interests, aspirations, habit of mind, particular temper and character;

- usage of certain motivational strategies. These include the use of: authentic professionally-oriented materials; game situations; collaboration in large and small groups in order to develop speaking skills, the interchange of views on the basis of team play; scenarios of possible professional situations dramatization of texts and dialogues; etc.

- organizing the process of education basing on skills integration principle;

- $\quad$ providing the highest possible students' involvement in educational process;

- establishing proper superintendence of foreign language lesson (accurate planning of the lesson, available teaching objectives to implement, clear guidance to tasks).

Motivational aspect is crucial for the activation of all psychological processes - cogitation, apperception, understanding and mastering of foreign language material. Ultimately, motivation increment, development of knowledge and intellectual activity will increase the efficiency of education process. The quality of foreign language training in the future will be the factor of specialist competitiveness on the labor market.

\section{References}

Bailey, cited in H. Douglas Brown. Principles of Language Learning and Teaching // 2nd edition, Englewood Cliffs, NJ: Prentice-Hall, Inc., 1987. p.117.

Bligh, D. A. What's the Use of Lecturing? // San Francisco: Jossey-Bass, 2000. p.384.

Crookes, G., \& Schmidt R. W. Motivation: Reopening the research agenda // Language Learning 41(4), 1991. pp. 469-512.

Dornyei, Z. Motivation in second and foreign language learning // The international Abstracting Journal for Language Teachers 31(3), 1990. pp.117-135.

Gorelova, J. Advertising Language as a Means of Forming Students' Cross-cultural Competence // Procedia - Social and Behavioral Sciences, Volume 152, 2014. pp. 669-672.

Grigorieva, E. Language Teaching Content Renovation in the Context of Higher Education Internationalization // Procedia - Social and Behavioral Sciences, Volume 152, 2014. pp.1144-1147.

Harmer, J. The Practice of English Language Teaching // Essex: Longman Press, 2001. p.51

Hudson, G. Essential introductory linguistics // Blackwell Publishers, 2000.

Ismagilova, L. , Polyakova, O. The Problem of the Syllabus Design within the Competence Approach based on the Course "English for Master Degree Students in Economics (Advanced Level)" // Procedia - Social and Behavioral Sciences, Volume 152, 2014. pp.1096-1100.

Kudryavtseva, M. Possibilities of Distance Learning as a Means of Foreign Language Learning Motivation among Students of Economics 
// Procedia - Social and Behavioral Sciences, Volume 152, 2014. pp. 1215-1218.

Lowman, J. Promoting Motivation and Learning [Text] // College Teaching, No. 38 (4), 1990. pp.136-139.

McMillan, J. H., and Forsyth, D. R. "What Theories of Motivation Say About Why Learners Learn." In R. J. Menges and M. D. Svinicki (eds.) // College Teaching: From Theory to Practice. New Directions in Teaching and Learning, no. 45, San Francisco: JosseyBass, 1991.

Sass, E. J. Motivation in the College Classroom: What Students Tell Us [Text] // Teaching of Psychology, No. 16 (2), 1989. pp.86-88.

Zalyaeva, E., Solodkova, I. Teacher-student Collaboration: Institute of Economics and Finance Kazan Federal University Approach /I Procedia - Social and Behavioral Sciences, Volume 152, 2014. pp. 1039-1044.

Whyte, Cassandra B. (2007). An Additional Look at Orientation Programs Nationally (reprint of 1986 article in same journal) // National Orientation Directors Association Journal 15(1), 2007. pp.71-77

Wigfield, A., Guthrie, J. T., Tonks, S., \& Perencevich, K. C. (2004). Children's motivation for reading: Domain specificity and instructional influences // Journal of Educational Research 97, 2004. pp.299-309. 